\title{
FTTH Network Expansion Modeling and Link Budget for Housing Locations
}

\author{
Ery Safrianti* \\ Electrical Engineering Department \\ Universitas Riau \\ Indonesia
}

*corresponding author: Ery Safrianti, esafrianti@eng.unri.ac.id

\author{
Widyantoro Tejo Mukti \\ Electrical Engineering Department \\ Universitas Riau \\ Indonesia
}

\begin{abstract}
The location of the research was carried out at Villa Melati Permai II Housing which is on the Melati Indah Street, Tampan District, Pekanbaru City. Villa Melati Permai II is categorized as middle to upper-class housing but does not have its access network. This research will make the modeling of FTTH (Fiber To The Home) networks with network feasibility parameters to produce quality and appropriate FTTH networks. Manual calculation on the feasibility of FTTH networks using the power link budget and rise time budget shows results within the feasibility limit, which does not exceed the maximum limit for the power link budget of $\mathbf{- 2 7} \mathrm{dBm}$ and rise time budget below the total time of bit rates. Calculation with NRZ (Non-Return to Zero) coding produces a downstream value of $0.2813 \mathrm{~ns}$ and upstream $0.562 \mathrm{~ns}$. System performance parameters that show signal to noise ratio and bit error rate deliver good quality. Signal to noise ratio exceeds the minimum limit of PT. Telkom standard that is $21.5 \mathrm{~dB}$ and the bit error rate does not exceed the optical link standard which is $10^{-9}$. Good performance is also shown by eye pattern in optical simulation that displays amplitude signals with the same time and shows clear differences between bits 1 and bits 0 .
\end{abstract}

Keywords- FTTH, power link budget, rise time budget, BER, eye pattern

\section{INTRODUCTION (HEADING 1)}

Telecommunication technology is currently overgrowing, resulting in the growth of diverse telecommunications services. The need for these services is not only in the form of voice but also data and video with large bandwidth. The use of the copper access network is considered not able to accommodate large bandwidth capacity and high speed. To meet these requirements, technology with large bandwidth availability and high data rates is needed. Fiber cable is a medium commonly used to provide broad bandwidth. The fiber media is not affected by electromagnetic wave interference.

When compared with copper cables, fiber optic cables can transport more extensive data. One example of fiber access networks is Fiber To The Home (FTTH). FTTH is an infrastructure by channeling data information from the provider center to the user area using optical fiber delivery media. The technology used by PT. Telkom Access in covering fiber to the home network is GPON (Gigabit Passive Optical Network). GPON is an access technology that is categorized as broadband access based on fiber optic cable. This GPON technology has advantages compared to other fiber optic technologies. GPON supports triple play applications, is more efficient in fiber optic processing, has reliable protection, and also has a $2.5 \mathrm{Gbps}$ bit rate for downstream and $1.25 \mathrm{Gbps}$ for upstream. Because the development and demand for internet, video and voice service needs will continue to increase, the researchers wish to conduct studies on FTTH network modeling using GPON technology. The design results will be analyzed using test parameters in the form of Link Power budget, Rise Time Budget, Signal to Noise Ratio (SNR), and BER (Bit Error Rate). Further testing will be carried out by simulation. Modeling simulations will be made on Opt System Software and will produce BER and Power Link Budget values. This value will then be compared with the calculation results.

\section{RESEARCH Methodology}

\section{A. GPON technology}

GPON configuration consists of 3 main parts namely OLT, ODC, and ONT. GPON itself can be used in point to point configuration or point to multipoint depending on implementation in the field. Triple play services on GPON in the form of voice, data, and video are multiplexed on Optical Line Terminal (OLT) and then transmitted via fiber optic media.

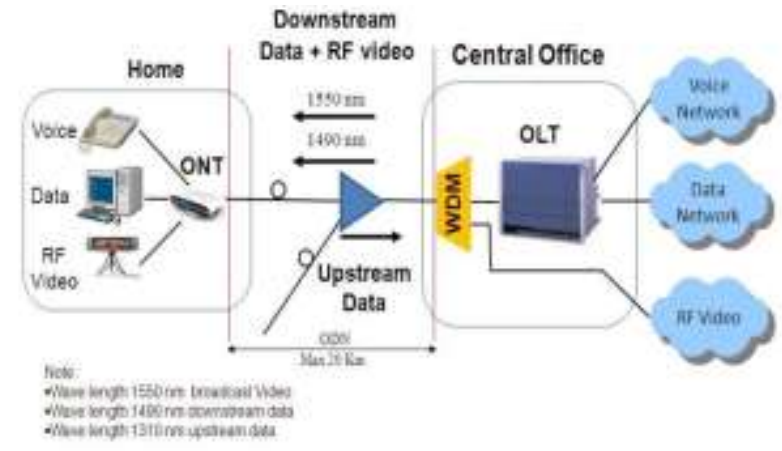

Figure 1. GPON Technology configuration [1] 
The difference in wavelength transmitted on FO is able to bring several broadband services (triple play service) simultaneously using Wavelength Division Multiplexing (WDM) technology. With the WDM technology information in the form of audio and video data can be transmitted in large quantities very quickly without having to convert light signals to electrical signals. GPON technology configuration could be seen in Figure 1.

\section{B. Fiber to the Home (FTTH)}

FTTH is a network consisting of active device OLT (Optical Line Termination) and ONT (Optical Network Termination) which is connected with fiber optic media and other supporting devices or can be called ODN (Optical Distribution Network) such as ODC, ODP, Splitter, ODF [2]. FTTH is a form of optical network that provides data services from provider to user equipment. Topologies commonly used in FTTH networks are point-to-multipoint (P2MP) and point-to-point (P2P). Point-to-multipoint topology is often combined with passive optical network technology (PON), and for point-to-point topologies using Ethernet. FTTH topologies as seen in figure 2.

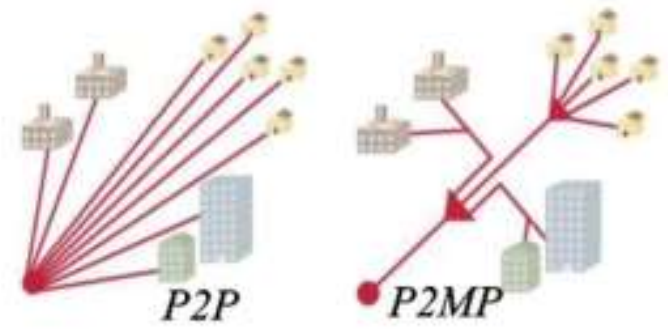

Figure 2. FTTH Topology [3]

\section{Parameter Design Feasibility}

In calculating the performance of optical fiber transmission, there are four parameters that need to be noticed to get a decent system so the results of the analysis obtained can be implemented in the field.

\section{a) Link Loss Budget}

The link loss budget is used for knowing the channel's total attenuation limit allowed because of the loss at each element (fiber losses, connectors, and connection) along the communication channel optics link.

Link loss budget calculations can be calculated with the following equation 1 [4]:

$\alpha$ total $=$ L. $\alpha f+$ Nc. $\alpha c+$ Ns. $\alpha s+$ Nsp.asp.

Where:

$\alpha$ tot $=$ total channel attenuation $(\mathrm{dB})$

$\mathrm{L}=$ optical fiber length $(\mathrm{km})$

$\alpha \mathrm{f}=$ optical fiber attenuation $(\mathrm{dB})$

$\mathrm{Nc}=$ number of connectors

$\alpha \mathrm{c}=$ connector attenuation $(\mathrm{dB} /$ connector $)$

$\mathrm{Ns}=$ number of connections

$\alpha \mathrm{s}=$ connection attenuation $(\mathrm{dB} /$ connection $)$

$\mathrm{Nsp}=$ number of splitters

$\alpha \mathrm{sp}=$ Splitter attenuation $(\mathrm{dB})$

\section{b) Power Link Budget}

Power link calculation budget aims to calculate the power budget

needed at the receiver so that the power level accept no less than minimum sensitivity. The formula as below [4]:

$$
\mathrm{P}_{\mathrm{rx}}=\mathrm{P}_{\mathrm{tx}}-\alpha \text { tot }
$$

\section{c) Power Margin}

Power Margin is the power remaining from the transmit power after being reduced from the link loss budget during the transmission process, power margin is required must have a value of more than 0 (zero).

Power margin is calculated by Equation 3 [4]

$\mathrm{M}=\left(\mathrm{P}_{\mathrm{tx}}-\mathrm{P}_{\mathrm{rx}}\right)-\alpha$ total $-\mathrm{SM}$

Where,

Ptx $=$ Transmitter output power $(\mathrm{dBm})$

$\operatorname{Prx}=$ Receiver sensitivity $(\mathrm{dBm})$

$\alpha$ total $=$ Link loss budget $(\mathrm{dB} / \mathrm{km})$

$\mathrm{SM}=$ Safety margin, $3 \mathrm{~dB}$ (provisions of PT. Telkom)

\section{d) Rise Time Budget}

Rise time budget is a method to determining the dispersion limit of a fiber optics link. The purpose of this method is to analyze whether network performance is overall has been achieved and meet the desired channel capacity. Total rise time can be calculated by equation 4 [4].

$$
t_{\text {sys }}=\left(t_{t x}{ }^{2}+t_{\text {chromatic }}{ }^{2}+t_{\text {modal }}{ }^{2}+t_{r x}{ }^{2}\right.
$$

Where:

$t_{t x} \quad=$ Rise time transmitter (ns)

$t_{r x} \quad=$ Rise time receiver (ns)

$t_{\text {chromatictx }}=$ Rise time chromatic dispersion (ns)

$t_{\text {modal }}=$ Not worth or zero because it uses single mode optics

\section{System Performance Parameters [5],[6]}

\section{Signal to Noise Ratio (SNR)}

Signal to Noise Ratio (SNR) is the comparison of signal power to noise power at the same point.

Signal to Noise Ratio $\left(\frac{S}{N}\right)=\frac{\text { Signal Power }}{\text { Shot Noise Power }+ \text { Amplifier Noise Power }}$

\section{Bit Error Rate (BER)}

BER is the bit error rate occurs in transmitting digital signals.

Where BER can be calculated by formula as follows:

$$
\mathrm{BER}=P e(Q)=\frac{1}{\sqrt{2 \pi}} \cdot \frac{e^{-\frac{Q^{2}}{2}}}{\mathrm{Q}}
$$

\section{RESUlts AND DisCUSSION}

Calculation of research feasibility in this research uses the furthest receiver link that is $7.04 \mathrm{~km}$ from STO Arengka, 
because if the most distant link is feasible (meets standardization), then the closer link will also meet standardization. To simplify the calculation, a design feasibility specification parameter is made as seen in Table 1.

Table 1. Specification parameter

\begin{tabular}{|c|c|}
\hline Spesification & Value \\
\hline furthest link & $7,04 \mathrm{~km}$ \\
connectivity receiver & $-27 \mathrm{dBm}$ \\
wide spectral & $1 \mathrm{~nm}$ \\
Downlink wavelength & $1490 \mathrm{~nm}$ \\
Uplink wavelength & $1310 \mathrm{~nm}$ \\
Wavelength of 1490 & $0.21 \mathrm{~dB} / \mathrm{km}$ \\
Wavelength of 1310 & $0.32 \mathrm{~dB} / \mathrm{km}$ \\
$1 \times 4$ splitter attenuation & $7.25 \mathrm{~dB}$ \\
$1 \times 8$ splitter attenuation & $10.38 \mathrm{~dB}$ \\
APC connector attenuation & $0.15 \mathrm{~dB}$ \\
UPC connector attenuation & $0.15 \mathrm{~dB}$ \\
rise time transmitter & $150 \mathrm{ps}$ \\
rise time receiver & $200 \mathrm{ps}$ \\
\hline
\end{tabular}

\section{A. Calculation of link loss budget}

Calculation of link loss budget can be seen from the parameter specifications in table 1 by using equation 1 then obtained:

\section{Downstream}

$$
\begin{aligned}
& =(7.04 \times 0.21)+(7 \times 0.15)+(12 \times 0,1)+(17,63) \\
& =21.35 \mathrm{~dB}
\end{aligned}
$$

Upstream

$$
\begin{aligned}
& =(7.04 \times 0.32)+(7 \times 0.15)+(12 \times 0.1)+(17.63) \\
& =22.13 \mathrm{~dB}
\end{aligned}
$$

The difference in results between downstream and upstream in the calculation of link loss budget occurs because optical fibers have different attenuation at specific wavelengths. Standard value from PT Telkom for pure channel attenuation maximum is $28 \mathrm{~dB}$ and minimum $18 \mathrm{~dB}$. The results show that the link loss budget is feasible because it doesn't exceed the standard set.

\section{B. Calculation of Power Link Budget}

Power link budget calculation use 3 scenarios and will calculated by equation 2 , the results are:

Downstream

$$
\begin{aligned}
& 5-21,35=-16,35 \mathrm{dBm} \\
& 3,75-21,35=-17,6 \mathrm{dBm} \\
& 1,5-21,35=-19,85 \mathrm{dBm}
\end{aligned}
$$

Upstream:

$5-22,13=-17,13 \mathrm{dBm}$

$$
\begin{aligned}
& 3,75-22,13=-18,38 \mathrm{dBm} \\
& 1,5-22,13=-20,63 \mathrm{dBm}
\end{aligned}
$$

3 scenarios used in the power link budget has an impact on the results received by ONT because the power sent by OLT has ranged from 1.5 to $5 \mathrm{dBm}$ so the calculation results power link budget can be seen in table 2 .

Table 2. Results from the power link budget

\begin{tabular}{|l|l|l|l|l|l|}
\hline \multirow{2}{*}{ OLT } & \multicolumn{2}{|c|}{$\begin{array}{l}\text { Power received by } \\
\text { ONT }(\mathrm{dBm})\end{array}$} & \multicolumn{2}{l|}{$\begin{array}{l}\text { Sensitivity } \\
\text { (ONT) } \mathrm{dBm}\end{array}$} \\
\cline { 2 - 5 } & Dw & $\mathrm{Up}$ & Min & Max & \\
\hline+5 & $-16,35$ & $-17,13$ & -8 & -27 & decent \\
\hline+3.5 & $-17,6$ & $-18,38$ & -8 & -27 & decent \\
\hline+1.5 & $-19,85$ & $-20,63$ & -8 & -27 & decent \\
\hline
\end{tabular}

\section{Calculation of Power Margin}

For power margin calculations using 3 scenarios will calculate by equation 3 with the results on the link loss budget. Then the results are:

(Downstream)

$$
\begin{aligned}
& 5-(-27)-21.35-3=7.65 \mathrm{~dB} \\
& 3.5-(-27)-21.35-3=6.15 \mathrm{~dB} \\
& 1.5-(-27)-21.35-3=4.15 \mathrm{~dB} \\
& (\text { Upstream }) \\
& 5-(-27)-22.13-3=6.87 \mathrm{~dB} \\
& 3.5-(-27)-22.13-3=5.37 \mathrm{~dB} \\
& 1.5-(-27)-22.13-3=3.37 \mathrm{~dB}
\end{aligned}
$$

\section{Calculation of NRZ Bitrate}

Parameter link specifications for estimation of total rise time is taken from transmitter device specifications (OLT), GPON receiver (ONT), fiber optic data sheet used and OSP design data FTTH. Parameter calculation of rising time budget can be seen in table 1 specifications design.

$$
t_{r} d w-\frac{0.7}{2,488}-0,2813 n s
$$

For upstream values in the same way, then obtained

$$
t_{r} \text { up }=\frac{0,7}{1,244}=0,562 \mathrm{~ns}
$$

\section{E. Simulation Analysis}

In the optical link simulation design with Opticsystem, network design FTTH is done in Downstream and Upstream by testing link feasibility power budget and bit error rate performance.

\section{F. Downstream Configuration}

On the simulation of the downstream optical link using a wavelength of $1490 \mathrm{~nm}$ with $2.4 \mathrm{Gbps}$ bitrates. On the optical fiber used was given an attenuation of $0.21 \mathrm{~dB}$. The total connector used is 8 pieces with each attenuation are 
$0.15 \mathrm{~dB}$, and there are 5 connections with attenuation $0.1 \mathrm{~dB}$ / connection. Image link simulation downstream can be seen in figure 3.

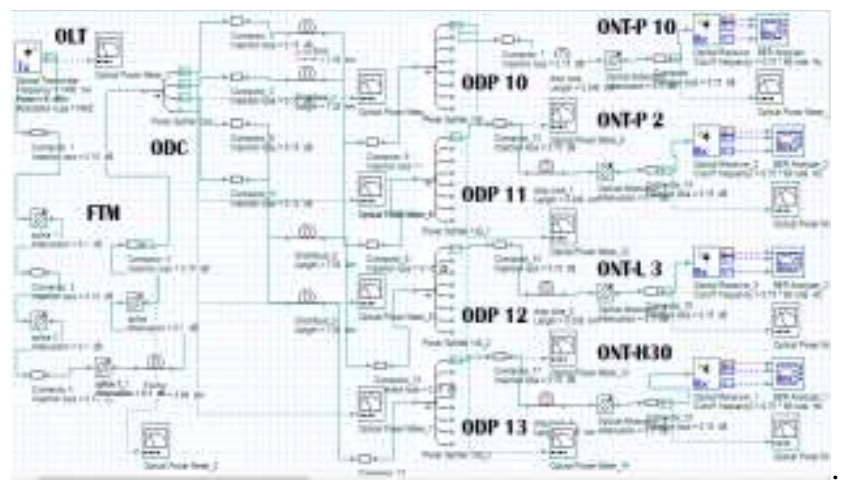

Figure 3. Downstream Simulation

Power sent using 3 scenarios as a comparison in results. In the simulation, design measurements are made using Optical power meter and BER analyzer.

Measurement with an optical power meter aims to measure the size of the link power budget or sensitivity received by the receiver. While the BER analyzer measurement is done to find out the BER value and the characteristics of the digital signal displayed in the eye pattern, the measurement results at the transmit power of 1.5 $\mathrm{dBm}$ using the optical power meter in the simulation can be seen in Figure 3. The power generated from a transmission power of $1.5 \mathrm{dBm}$ produces attenuation of $-19,326 \mathrm{dBm}$. Measurements made using BER Analyzer to find out the bit error value in the simulation can be seen in Figure 4.

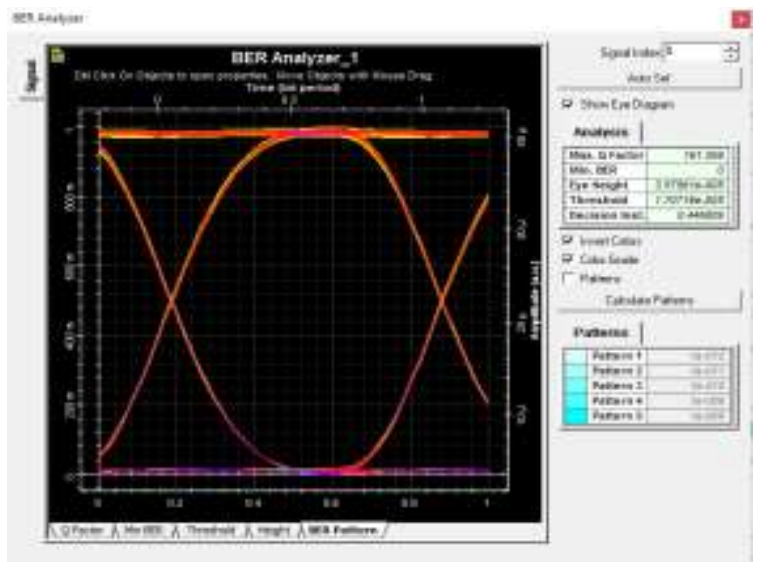

Figure 4 Display of downstream eye pattern for $1.5 \mathrm{dBm}$ transmit power

BER value generated from a transmit power of $1.5 \mathrm{dBm}$ produces an amount of 0 which shows no error bits in the transmission process. Good performance is also indicated by the eye pattern, which shows clear differences from bits 1 and bits 0 .

\section{G. Upstream Configuration}

Measurements are made on the design upstream simulation using a wavelength of 1310 with a bitrate of 1.25 Gbps. In the same way, measurement carried out in 3 measurement scenarios. On transmission power of $1.5 \mathrm{dBm}$ measurement of link power budget for the simulation can be seen in Figure 5.

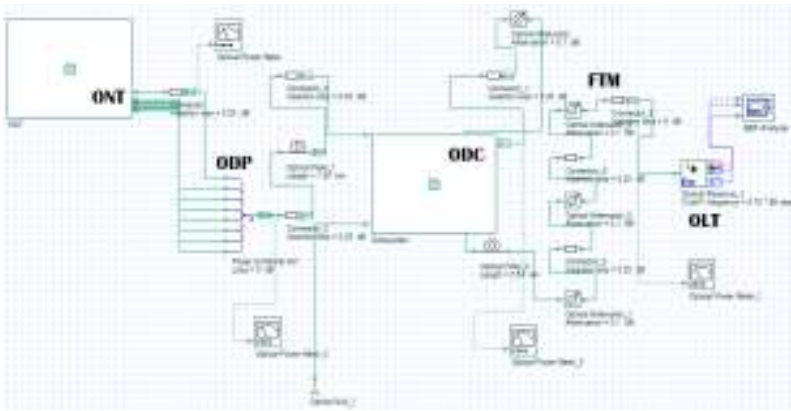

Figure 5. Upstream simulation

Power received by OLT from ONT with transmit power $1,5 \mathrm{dBm}$ produce attenuation of $-20,201 \mathrm{dBm}$. Measurement use BER Analyzer at upstream can be seen in figure 6

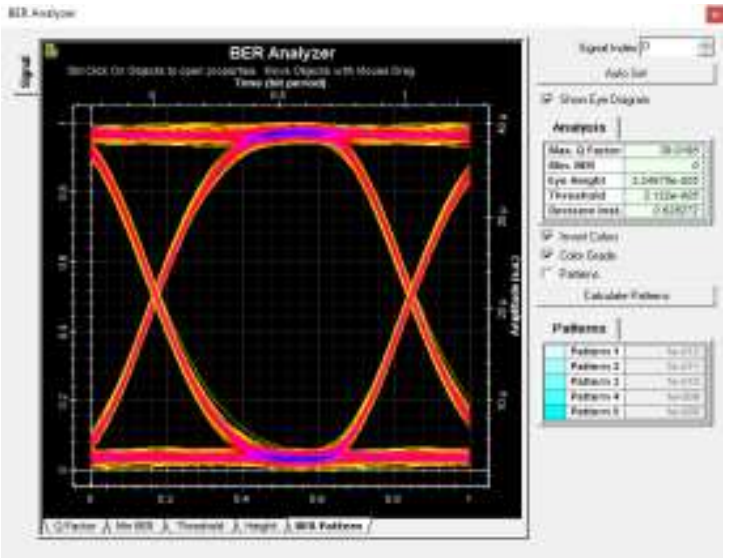

Figure 6 Display of upstream eye pattern for $1.5 \mathrm{dBm}$ transmit power

Based on the simulation results in the BER value generated from a transmit power of $1.5 \mathrm{dBm}$ produce a value of $1.64506 \times 10^{-84}$. These results indicate that at the upstream, OLT identifies information of 10-84 bits with an error of 1.64506 bits in a unit of transmission time to the recipient. The results obtained from the BER Analyzer at the upstream and downstream are declared feasible because the value generated from the two links is smaller than the standard BER value for optical fiber communication is $1 \mathrm{x}$ $10^{-9}$.

\section{H. Analysis of Design Results}

The design results are carried out with test the results of the calculation of the link power budget and bit error rate with the simulation results obtained from measurements on the optical power meter and BER analyzer. Comparison of the link power budget using manual calculation results with the simulation results can be seen in table 4 .

$\operatorname{Pr}$ comparison results between calculations and simulations show value differently, but still at the limit minimum network design feasibility. Pr differences obtained from simulation caused by attenuation produced by devices in the simulation are smaller than attenuation used in 
calculations. Because each device is on its specifications has a different attenuation range in its use.

Table 4. Comparison between manual calculation and

\begin{tabular}{|c|c|c|c|c|}
\hline \multirow{3}{*}{ OLT } & \multicolumn{3}{|c|}{$\begin{array}{c}\text { Power receimulat by } \\
\text { ONT(dBm) }\end{array}$} & \multicolumn{2}{c|}{$\begin{array}{c}\text { Sensitivity } \\
(\text { ONT) dBm }\end{array}$} \\
\cline { 2 - 5 } & Dw & Up & Min & Max \\
\hline+5 & $-17,13$ & $-16,35$ & $-16,70$ & $-18,82$ \\
\hline+3.5 & $-18,63$ & $-17,85$ & $-18,20$ & $-17,32$ \\
\hline+1.5 & $-20,63$ & $-19,85$ & $-20,20$ & $-19,32$ \\
\hline
\end{tabular}

Comparison of BER values obtained from simulation measurements with BER calculation results is obvious, in BER simulation results for downstream, eye pattern produces a perfect signal which results in BER analyzer not identifying errors in bits, so the BER value is 0. At upstream simulation results, error bit occurs at transmitting power 3.5 and $1.5 \mathrm{dBm}$. On manual calculation, bit errors occur in the process upstream and downstream transmission. However, on the results of both performances for manual calculations and simulations are still at the limit of good performance with the standard limit BER on the optical link is $10^{-9}$.

\section{CONCLUSION}

1) Calculation of the link power budget using 3 scenarios with different transmit power, namely 1.5 $\mathrm{dBm}, 3.5 \mathrm{dBm}$, and $5 \mathrm{dBm}$ resulting in a Pr value in the downstream range of $-16.31 \mathrm{dBm}$ to -19.85 $\mathrm{dBm}$ and for upstream amounting to $-17.05 \mathrm{dBm}$ to $-20.63 \mathrm{dBm}$. The power link budget calculation is in the excellent category which is still at the receiver sensitivity limit, which is $[-27 ;-8] \mathrm{dBm}$.
2) Rise time budget calculation using NRZ coding, for upstream obtained total rise time of $0.25017 \mathrm{~ns}$ and for downstream values obtained at $0.265994 \mathrm{~ns}$ so that the design results in RTB calculations with the farthest distance are said to be feasible because the amount of time obtained still at the total rise time limit of $0.2813 \mathrm{~ns}$ and $0.5626 \mathrm{~ns}$.

3) Based on the simulation results of the Optisystem on the measurement of Pr, the design is categorized as feasible because the results obtained are above the standards set by PT. Telkom is $-27 \mathrm{dBm}$. The upstream produces a Pr value of $-16,623$ to $-20,201$ $\mathrm{dBm}$ while the downstream value of $\mathrm{Pr}$ is at -15.775 $\mathrm{dBm}$ to $-19,326 \mathrm{dBm}$.

4) Good performance is also shown in the eye pattern at the upstream and downstream shows no decrease in noise in amplitude signals and time shifts in the transmission process so that signal characteristics can be seen by showing signals formed like the eye which means the clear difference of bits 1 and bit 0 .

\section{REFERENCES}

[1] PT Telekomunikasi IndonesiaTbk, Modul 1 Konfigurasi FTTH, 2014.

[2] FTTH Council, "FTTH Infrastructure Component and Deployment Methods", Europe at the Speed of Light, 2007.

[3] FTTH Council, "FTTH Handbook .Deployment and Operation Committee", 2016.

[4] Faruqi, Ismail, "Studi Perancangan Jaringan Akses Fiber to The Home (FTTH) dengan Menggunakan Teknologi Gigabit Passive Optical Network (GPON) di Perumahan CBD Polonia Medan", Skripsi Sarjana, Teknik Elektro, Universitas Sumatera Utara, Medan, 2014.

[5] Huawei Technologies, "The Requirements and Evolution to Next Generation Optical Access Network", 2015. 